- lite sction might be induced by subetances in themsolves poesesing no specific or poisonous qualities.

From experiments wich have been now varied in a thousand ways, and most unnecessarily ropested, it has been proved beyond a doubt that the syphilitic poison may remain in contact with an abraded surface, or may be inserted benesth the cuticle, and allowed to remain there for three, four, or even five days, and no absorption may occur. If, during this time, an inflammatory action is set up, which is incompatible with specific adhesive inflammation, no general infection will follow. If, for instance, the part is made to slough by the application of caustic, as soon as the slough separates, a simple sore alone will remain. From this, it is ovident that a certain time must elapse after the application of the syphilitic poison before any absorption can take place. This requisite period of incubation it is that secures the system against infection in cases where, from the first, ulcerative or suppurative inflammation has taken place. A part, in the course of being contaminated, becomes by these processes dissolved or removed before the act of absorption can be completed. Fresh parts, which may continue to be attacked, are destroyed before they can act as the channels of infection to the constitution. Hence occasionally arise those extensive local intractable ulcerations which have received the name of serpiginous or creeping sores. These, howerer formidable they may be as local diseases, do not give rise to secondary syphilitic symptoms.

We have here the secret of the absence of constitutional results after artificial inoculation in the numerous experiments that have been made on syphalisation. These experiments have been tried only on those whose systems were already under the influence of the poison; and it appears to be a very general law that, in such cases, any fresh inoculations pass rapidly into suppuration, or ulceration-processes, as I have said, incompatible with the specific and infecting kind of inflammation. Where several artificial inoculations have been performed, and these inoculations have at once suppurated, the circumstances are in many respects similar to those in which any patient would be placed if he had a suppurating bubo. Many small spots of suppuration, and one large spot, I conceive to be nearly equivalent to each other; in neither case is the poison absorbed from these secondary inoculations. This circumstance it doubtless is that has given some of our continental brethren the idea that repcated inoculation may be a preventive against future syphilitic infection.

It is, I believe, undoubtedly true that, while a syphilitic sore is undergoing ulceration or suppuration, any similar affection arising from fresh inoculation will do the same; and it is quite possible that this tendency may be kept up by repeated inoculation for an indefinite time. During this period, no fresh absorption of syphilitic poison will take place. The same immunity is afforded by a suppurating bubo during its continuance, and perhaps for a considerable time after it has healed. But, in either case, allow an interval to elapse during which this tendency to ulceration or to suppuration shall have worn itself out, and the system will aguin become subject to genuine syphilitic infection, and be again liable to fresh forms of secondary disease.

From all the observations which have now been made, I conclude that the idea originated by Hunter, and received by his followers, that the syphilitic poison is taken into the system by the lymphatic vessels, is, to say the least, entirely devoid of proof. The real way in which the system does become infected may, I beliere, be traced in another and much more satisfactory manner.

When syphilitic inoculation takes place in a healthy person, and the regular course of the disease is not interfered with, $t$ wo distinct processes may be recognised; one, that by which the affected tissues become infiltrated with lymph; the other, by which this effused matter is removed. This latter result may be accomplished by sloughing, by ulceration, in the natural process of growth, or by different modifications of these. But, beyond the parts immediately involred in these processes, other actions are going on of a more cubtle nature, and not so easily appreciated by our senses.
In the absence of more positive knowledge, , Te mas ascribe these to the molecular changes in the nutrition of the surrounding parts. That such actions are in active operation beyond the parts where any visible or sensible change has taken place, may be readily demonstrated, although we may be unable to define their exact nature. Were this not the case, we should have nothing to do in the case of a primary syphilitic sore but entirely to remove the ulcerated and indurated tissues, and the disease would, as far as the part is concerned, be at an end. Experience proves that such is very far from being the case. When a syphilitic sore is removed by excision, as may readily be done when it is situated on the extremity of the prepuce, the cut surface will. in a few days take on the specific action. This I have verified even when the greatest care has been taken not to allow any other matter from the chancre to come into contact with the cut surface. Such an action taking place in a part apparently healthy, at some little distance from the original sore, presupposes some antecedent change in the original sore, presupposes some a change produced by the infecting poison, but not capable of being appreciated solong as the diseased action had its development in its original situation. As soon, however, as the first centre of the morbid action is remored, a similar disease is induced upon the neighbouring cut surface. The observation of such cases demonstrates the existence of a subtle morbid process beyond the parts at first sensibly affected, and necessarily producing some change in their nutrition.

It appears under these circumstances much more in accordance with that which is known to happen in the case of the absorption of other poisons, to suppose that the blood circulating through the tissues in which these morbid actions are going on is directly influenced, than to refer the symptoms to the passage of the poison primarily through the absorbent system. When the constitution becomes affected in consequence of the inoculation of the vaccine or the variolous poisons, the lymphatic glands appear certainly to perform no essential part of the process. Few indeed have thought it necessary to inroke the aid of the absorbent system to account for the action of these poisons upon the animal economy; and I believe that it is equally unnecessary in the case of the poison of syphilis.

At present, I have only considered the different kinds of inflammatory affections produced by syphilitic contagion. The existence of similar non-inflammatory modes of infection (such as the absorption of the syphilitic virus without. any change of structure in the parts to which it is applied, or the production by some means of tubercles or excrescences not having an inflammatory origin) form a subject for separate consideration.

\section{EXPERIMENTAL INQUIRY INTO THE EFFECTS OF INJECTING PUS INTO THE VEINS OF ANIMALS.}

\section{By JOSEPH SAMPSON GAMGEE, Esq.}

Froy the brief consideration of my experimental inquiry into the effects of injecting pus into the veins of animals, published by Mr. Henry Lee in the Association MedicaI JodRNAL for Dec. 23rd, it is evident that he adheres as firmly as ever to the doctrine which he propounded in 1850 , and that he has been in no degree impressed with my objections to it as being of much weight. He tacitly admits, indeed, that I have exposed the fallacy of one set of experiments on which he founded it, but he "cannot for a moment allow (as I appear to have inferred) that the conclusions arrived at depend upon the accuracy of any one set of experiments": but I anticipate that, however sanguine be Mr. Lee's confidence in his principles and conclusions, he will find it difficult to hold and inculcate them, unless he can maintain intact the experimental basis upon which he founded them. The matter is essentially one of experience; and if Mr. Iree's conclusions can be proved to be the result 
of a las mode of arguing upon facts incorrectly obserred, ther will be untenable.

Mr. Iee first proceeds to defend his experiment of mixing some pus with blood out of the body, and he does so by endeavouring to show that I have not correctly appreciated his meaning; but the words of his text are so clear, that I acquired a very accurate notion of their precise signification the very first time I read them. In the preface to his work, we find: "The simple experiment of mixing some pus with healthy recently drawn blood will at once show that such a combination cannot circulate in the living body. ... It appears not a little surprising that this, perhaps the simplest and the most instructive experiment that can be performed in reference to the subject of the formation of purulent deposits, should not have been resorted to in preference to others, which have been difficult in their execution, and inconclusive in their results."* That Mr. Lee should have considered his observation very valuable, is natural enough; but that he should have extolled it above such experiments as those of Castelnau and Ducrest, and of Sedillot, and sweepingly dealt with them as "inconclusive in their results", excites surprise; for it would be difficult to produce any set of experiments in pathology the results of which were more perfectly conclusive, and of higher practical utility.

"It appears strange to Mr. Lee that I should have inferred from his writings that pus could never be made to pass into the circulation." I beg to state that I never drew this inference; but what I do infer from Mr. Lee's writings, and what I believe to be in opposition to facts, is his belief that the coagulating power with which healthy blood is endowed prevents pus circulating with it, even when injected into one of the large veins. In his preface, he states that "a combination of pus and blood cannot circulate in the living body." At page 5, he observes that, "when the pus introduced is in any large quantity, the coagulation of the blood is at once determined, and the entrance of pus into the circulation thereby prevented." At p. 44, "In animals in perfect health, the pus cannot enter the circulation, as has been already shown, or can only do so after the blood has partially or entirely coagulated round it, and the coagulum has subsequently become broken up." At p. 45, "Some change must previously have passed in the blood, by which its coagulating power is impaired, or some unusual mechanical means must have been employed, before the pus can find its way in the course of the circulation. The contradictory statements which have been made by those who have injected pus into the veins, may thus be reconciled, by taking into account the power exercised by the blood in the experiments which have been made. There can be little doubt that while, in some instances, a portion of the pus has been forced into the general circulation, in the majority of cases it has been detained in the veins into which it was first introduced, and has never become part of the circulating fluid." The experiments performed by Castelnau and Ducrest, Sćdillot and myself, supply abundant evidence in opposition to these statements; and any one may, by repeating them with the necessary care, satisfy himself that, when pus has been injected into the vascular system, it moves on unchecked, to all appearance, as rapidly as the blood itself, and that Mr. Lee erred in conceiving the above quoted opinions-an error referrible in part to his predicating vital phenomena from observing the changes in dead matter out of the body, and in part to arguing upon a set of experiments conducted without due regard to the exclusion of fallacies.

Should any doubt still exist as to Mr. Lee's opinion, it admits of being cleared up by a further quotation from his

* In the continuation of the preface, we read that "it has been remarked by Sir Charles Bell, that we can seldon rely upon the answers that are ex. by Sir Charles Bell, that we can seldom rely upon the answers that are ex feeling of mankind; and that it is our duty, if experimeuts are performed, at all erents to prepare for them by the closest possible application of ou reason, and so to narrow the question as to be certain that advantage may bo gained by our proceedings." What unhappy fate would awajt the sciences of companative physiologg and pathology, if these rery tender feelings an anxiety to narrom the question $\&$ priori prerailed at all extensively, it does not require much prophetic wisdom to foretell. work. At p. 44, he remarks, "In cases where, from long continued disense, and the repented introduction of vitiated fluids into the circulation, the blood has lost its power, there appears no reason to doubt the correctness of Dr. 86 dillot's observations; and it is probable that pus globules may then circulate with those of the blood." "On a matter of such vital importance to the existence of his doctrine, it would have been well if $\mathrm{Mr}$. Lee, instead of satisfying himself with saying that, under such and such circumstances, there appears no reason to doubt that pus globules may circulate with those of the blood, had had recourse to experience to confute the French surgeon's observations, which essentially refer to matters of fact. To say, apart from experience in support of a doctrine, that the circulation of pus in the blood is prevented by the power of the former to induce coagulation; to say, I repeat, apart from experience, in support of such a doctrine, that there appears no reason to doubt the possibility of pus circulating with the blood when it has lost its coagulating power, is begging the whole question." (See my memoir on Pyamia, in Associatrox Medical Jodrasi, March 4th, 1853.)

In many parts of his work, Mr. Lee quotes his experiments on living animals to prove that the entrance of pus into the circulation is prevented by the coagulating power of the blood; but careful study of the narrative of his experiments supplies the strongest possible evidence in favour of the belief that, in the cases in which he fancied he felt the vein full, and referred this to coagulation of the blood within it, the real condition of things was distension of the cellular tissue around the vein with blood, which easily makes its way into its meshes, mixed with the pus, which was not injected into the vein at all, as he supposed it to hare been. The reasons for this criticism will be found in my communication of the 9th Dec.: they have, I think, gained additional strength from the fact that Mr. Lee has not attempted to reply to them, which I think he would have done, had he been able to do so successfully; for he cannot but have discerned that, unless they are refuter, the experimental foundation of his doctrine is well nigh demolished:-1stly. Because his experiments on living animals (the objects of the criticism in question) constitute a great part of that foundation. 2ndly. Because, if those experiments are fallacious, he can claim very little, if indeed any merit, for his observation of the influence of pus in accelerating the coagulation of blood out of the body. It would be unwarrantable to predicate $d$ priori, from such an observation, what was likely to occur in the living body; but such predication, in direct opposition to what observation has proved actually to occur in the living body, is altogether inadmissible.

It has appeared strange to Mr. Lee that I should have endeavoured to prove, in supposed opposition to his experiments, that the "circulation of pus in the blood is perfectly possible". This is not what I endeavoured to prove in opposition to Mr. Lee; but what I believe to have proved in opposition to him is, "that, when pus is fairly injected into a vein, there is no obstacle to its moving on with the current of blood" (first conclusion deduced from my experiments). To be more explicit, I may say that, from what I saw in my experiments, conjoined will what has been proved by Castelnau and Ducrest, and by Sédillot, I am convinced that Mr. Lee is in error in believing that, "when pus is introduced (into a vein) in any large quantity, the coagulation of the blood is at once determined, and the entrance of pus into' - 1 circulation thereby prevented"; and that he is equally in error in saying, that "some change must previously have passed in the blood by which its coagulating power is impaired, or some unusual mechanical means must have been employed before the pus can find its way in the course of the circulation".

There is only one of $\mathrm{my}$ experiments to which Mr. Lee has particularly alluded; it is the one in which, after $I$ injected into the jugular vein of a horse two drachms and a scruple of good pus, diluted with equal quantity of water, the animal fell and died in a couple of minutes. $\mathbf{M r}$. Lee has transcribed my account of this experiment, but has 


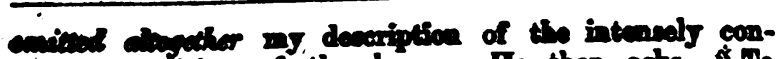
ruted condition of the lunge. He then adk, \& To what are to be attributed the sudden and fatal efiects in Mr. Gamgee's case f* I answer, to the coagulation of the blood in the heart." I presume it is to the same case he refers when, in an earlier part of the same paper, he observes, "Mr. Gamgee has himself furnished the eridence that vitiated blood.... will not always remain fluid in the ventricles of the living heart."

I am at a loss to say how my account of the experiment could afford even a semblance of a foundation for such conclusions. Here are the facts of it briefly stated. I injectod a mixture of pus and water into the jugular vein of a perfectly healthy horse. He immediately began to heave at the flanks, and fell; when down, he breathed with great difficulty at least four times quicker than natural, and in two minutes died. At the examination of the body, four and a half hours afterwards, the right cavities of the heart were found filled with dark currant-jelly-like clotted blood; the left cavities contrined a smaller clot; the lungs were very intensely congested. $t$ Is this the case which proves that vitiated blood will not always remain fluid in the ventricles of the living heart? Is it not unmistakably plain from the symptoms before death, and the typically dereloped anatomical characters ascertained by dissection, that the cause of death was asphyxia? In his anxiety to reconcile the result of my experiment with his doctrine, Mr. Lee has lost sight of two no less important facts than the congested condition of the lungs, and the time at which I performed the autopsy-four and a half hours after death. By not taking cognisance of the former, he was led into the error of regarding the clot in the heart as the cause of death; while, by overlooking the latter fact, I mean the time of the autopsy, he felt himself free to conjecture that the clot in the heart had formed during life.

Mr. Lee has of course a perfect right to please himself in believing that he has fully demonstrated his doctrine, and to treat lightly the facts that are opposed to it; but how far he is warranted in such belief, others must judge from the evidence before them.

Palazzo Corsi, Florence, Jan. 1854.

\section{BIBLTOGRAPHICAI NOTICES.}

The Digeases of the Rectux. By Richard Quain, F.R.S., Professor of Clinical Surgery in University Cellege, and Surgeon to University College Hospital. Illustrated with lithographic plates. 8vo. pp. 285. London : 1854.

ThIs treatise is eminently of a practical character, and contains much original and valuable matter. It is not, indeed, a literary compilation, but rather an exposition of the author's opinions and practice in these diseases, and as such, and coming from a surgeon of great experience and undoubted ability, will amply repay an attentive perusal.

The first subject treated of is Hæmorrhoids, which is discussed at some length and illustrated with numerous cases. Their frequent connexion with morbid states of the constitution and more especially a congested condition of the chylopoietic organs, is pointed out, and the indications of treatment deducible from this fact are clearly laid down.

In the simpler forms of the disease not requiring surgical interference, Mr. QUaIN deems it sufficient to enjoin rest,

- Mr. Lee has associsted with mine mn experiment which appears to have been atlended with results similar to it, in the hands of Dr. Mackenzie. II forbear commenting upou it, because I have not had the opportunity of pacusing an woount of it in full. Thongh I have for wome days been in expectetion of recejving tho last volume of the Xedico-Chirurgical Transcetions, containing Dr. Mackeszie's memoir, it has not yet reached mo, and I have therefore been

+ I pousesses. m brother Jotw, two sections of this horse's langs. They aro accurately

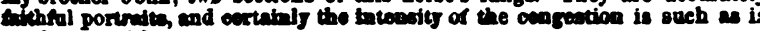
revoly met wilh.

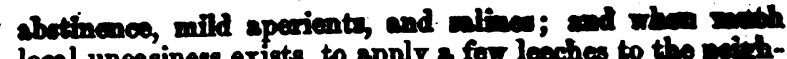
local uneasiness existe, to apply a for looches to the whithbourhood of the piles, with warm fomentations; should thoy
hare protruded and become strangulated or inflamed, we hare protruded and become strangulated or ininmed, we means the acute symptoms have subsided, he urges tho necessity of endesvouring to prevent a recurrence of the attacks, and considers that this should be accomplished by hygienic rather than by medical treatment.

"But how is relief, aud that as permanent as possible, to be afforded in such a case? My answer is, not by the continued use of drugs, but by attention in detail to the various circumstances which conduce to the maintenance of a healthy state of the system. Thus while the diet is regulated-made more moderate in quantity as well as stimulating - the skin is to be thoroughly cleansed by daily ablution. Active exercise is to be taken for at least a couple of hours each day, afoot or on horseback; and the effect of this, it is to be borne in mind, is all the more salutary if a degree of perspiration accompanies the vigorous exercise of the limbs. By the action of the skin (which is one of the great emunctories of the system), and the increased nutrition of the muscles, the internal congestion, before adverted to, is removed or prevented, and a feeling of elasticityof bealth, in a word, is substituted for the former feeling of heaviness and discomfort." (pp. 8-9.)

In treating of internal piles, the author enters into a consideration of the nature of the hæmorrhoidal tumour the probable cause of the disease, the circumstances which render an operation necessary, and the object and plan of the operation. We quote the following observations on the anatomy of hæmorrhoids.

The author having informed us that the rectum is largely supplied with blood, but that the distribution of the bloodvessels is not the same throughout, observes that-

"Over the greater part, the arteries and veins, taking both systems of vessels as following the same course, penetrate the muscular coat at short intervals, and at once divide into small branches, which hold a transverse direction, and form a network by their communications with the snbdivisions of other similar vessels. In the lower part of the bowel, for the length of about five inches, the arrangement is very different. Here the vessels have considerable length, and their direction is longitudinal. Penetrating at different beights they are direeted downwards in parallel lines towards the end of the gut. In their progress downwards, they communicate with one another at intervals, and they are still more freely connected near the orifice of the bowel. The arteries in this place all join by transverse branches of good size; the veins form loops and communicate with equal freedom." (pp. 30-31.)

This anatomical disposition of the blood-ressels of the rectum is illustrated by two neatly executed lithographic plates, and the author proceeds to point out that it is in the inferior loops of the veins thus described that the hrmorrhoidal tumour originates.

For the removal of internal piles, he exclusively employs the ligature, and regards excision as under all circumstances a dangerous proceeding. On the other hand, he prefers excision for external piles, but adds that in certain cases the ligature may be used, provided the skin be completely divided in the track of the ligature before it is drawn tight. "It is not allowable in any case", he remarks, "to include in a ligature the external hæmorrhoid without this proceeding, on account of the extreme suffering it would give rise to, which might even compromise the life of the patient." When hæmorrhage occurs, or is threatened after excision, the author is in the habit of passing a pin, constructed for the purpose, through the bleeding part, and orer the ends of this twisting a few turns of ligature vith sufficient tightness to control any bleeding. The pin may be removed in twenty-four hours.

The next subjects treated of are Abscess and Fistula in Ano, of which numerous illustrative cases are given. In regard to abscess, the author is of opinion that it is best to lay it open at an early period, and he thinks that an incision into the tumour, even before matter has fully formed, is very likely to check the tendency to suppuration, and thus to diminish the amount of diseased action. When howerer the matured abscess has been opened, and it is 